\title{
Accessible Video-Call Application on Android for the Blind
}

\author{
Nutnicha Maneesaeng, Proadpran Punyabukkana, and Atiwong Suchato
}

\begin{abstract}
Video call function on smartphone, if properly implemented, can become a vital tool for people with visual disabilities to communicate with their assistants. We evaluated six popular video call applications on Android: Line, Skype, Hangouts, Tango, WeChat and Viber, and found that none of them was readily accessible for the blinds. Nonetheless, Tango outperformed their competitors as it could accomplish six out of seven mandatory tasks. In terms of efficiency, Hangout stood out because it was able to complete five out seven tasks with the least amount of time. Regarding effectiveness, no significant difference was found among the seven applications. We then analyzed their user interface and proposed a guideline as an extension to WCAG 2.0. Finally, we simulated a new UI based on our guideline and ensure accessibility and minimum swipes. The proposed design was evaluated by a blind user and found an improvement on five of seven tasks. The overall improvement was $53.15 \%$.
\end{abstract}

Index Terms-Accessibility, video-call, smartphone, android, user interface, navigation, assistive technology.

\section{INTRODUCTION}

People with disabilities and seniors have embraced the concept of Independent Living. For the blinds, though they are able to get around independently, they may not be able to accomplish some tasks on their own. Examples include navigation in an unfamiliar environment or looking for lost items. When task that requires sight occurs, the blinds often turn to their personal assistants. With the availability of smartphones in this day and age, video calls can become extremely helpful as they provide visuals to the assistants to guide the blinds through different situations. People with visual disabilities most rely on speech input and output when using mobile technologies. Major smartphone manufacturers embed text-to-speech capability with their operating systems; Voice Over capability on iOS [1], Talkback on Android [2]. However, there is no guarantee that non-visual users would be able to use every application seamlessly. We are specifically interested in exploring video-call applications on Android to assist them with the navigation task. Video-call is an answer for blind users specifically when they seek help from sighted person. For example, one may want to ask for direction to a specific place that he or she may not be familiar with, by showing the helper with current place through video. Moreover, he or she may need help finding lost items through the use of videos. There are many more situations where

Manuscript received January 5, 2015; revised March 2, 2015.

The authors are with Chulalongkorn University, Bangkok, Thailand (e-mail: nutnicha.ma@student.chula.ac.th, proadpran.p@chula.ac.th, atiwong.s@chula.ac.th). non-sighted users desperately need help when there is no one around or from ones they trust.

This study comprises three parts; 1) the investigation of existing applications, 2) the accessibility assessment, and 3) the design and implementation of a new video call application for the blind. In Part 1, we identified six popular video call applications on Android; Skype, Line, Tango, HangOut, WeChat, and Viber. Comparisons were made among the six applications based on their accessibility to a blind user performing pre-defined tasks. We measured their efficiencies as well as throughputs while observing ease-of-use and difficulties during the experiment. In Part 2, we analyzed the actions required to complete each task for each of the applications based on Web Content Accessibility Guideline (WCAG). In Part 3, we proposed a new design of a video call application and measured its efficiency.

\section{BACKGROUND}

The background can be categorized into three parts; 1) screen reader and Text-to-Speech, 2) accessibility issues and Web Content Accessibility Guideline (WCAG), and 3) Usability measurement.

\section{A. Screen Reader and Text-to-Speech}

Screen reader is an essential software that allows blind users to interact with smartphones [3]. An interview from an expert blind user [4] revealed that most blind users are familiar with swiping and double tapping screens to access their mobile apps using screen reader. Screen reader is always tied to text-to-speech (TTS). Screen reader anaylyzes which texts are to be read and send the text along with meta-data to specified text-to-speech to read aloud in the language specified. Major smartphone manufacturers embed their screen reader and TTS with their phones. IOS offers VoiceOver capability, and Android, Talkback. However, [5] found that Android speech services are not properly accessible, nor usable by blind users. Thus far, no research was carried out to assess the usabilities and accessibilities of screen readers and TTS on smartphone for the blinds.

\section{B. Web Content Accessibility Guidelines 2.0 (WCAG 2.0)}

The objective of Web Content Accessibility Guidelines (WCAG) is to suggest standard for web content accessibility that meets the needs of individuals, organizations, and governments internationally, be they people with disabilities or others [6]. WCAG is primarily intended for web content developers (page authors, site designers, etc.), web authoring tool developers, web accessibility evaluation tool developers, and others who want or need a standard for web accessibility. [7] proposed top eight concerns from persons with disabilities 
and best practices for user interface designers. They include concerns from people with visual disabilities, hearing disabilities, physical disabilities, and cognitive disabilities. In this study, we would employ these eight concerns in our preliminary steps.

\section{Usability Measurement}

As far as usability measurement is concerned [8], this study employed the technique of cognitive walkthroughs [9], [10], which is a technique for evaluating the design of a user interface. This technique was chosen because it allows the evaluation to be conducted with a group of users who may not be subject-matter experts [11]. In our study, we asked a blind user to evaluate the usabilities of the specified video-call applications on the first part to perform main video-call tasks. For the later part, we asked non-blind users to perform the same tasks in order to measure time and efforts put to complete each task.

\section{INVESTIGATION OF VIDEO-CALL APPLICATIONS ON ANDROID}

We identified six popular video call applications on Android; Line, Skype, Tango, WeChat, Hangouts, and Viber. The investigation of the usabilities and accessibilities of these applications comprises three parts; 1) Task identification, 2) Experimentation, and 3) Evaluation.

\section{A. Task Identification}

Our goal is for a blind user to place a video-call to his or her personal assistant asking for help such as navigation or finding lost items. To do so, the most fundamental task is to place or receive the call. To end the conversation, each party should be able to disconnect the call. In the case that the line is cut off for any reasons, call needs to be reconnected by either party. When a blinder caller seeks help, most likely, the assistant would want to utilize back camera, not the front one capturing the caller. In which case, blind caller should be able to switch the camera upon the assistant's request since all applications' default front camera. One other required task for every application is for the caller to register when they use the application for the first time and add new friends to store their numbers. Table I summarizes all seven tasks that we asked the user to perform during the investigation.

\begin{tabular}{|c|c|c|}
\hline Code & Task name & Description \\
\hline $\mathrm{T} 1$ & Register & $\begin{array}{l}\text { User registers as the first time of } \\
\text { using }\end{array}$ \\
\hline $\mathrm{T} 2$ & Add a new friend & User adds a new friend \\
\hline $\mathrm{T} 3$ & Make a new call & $\begin{array}{l}\text { User selects a friend and makes a } \\
\text { new call }\end{array}$ \\
\hline $\mathrm{T} 4$ & Receive a video call & User receives an incoming call \\
\hline T5 & Switch camera & $\begin{array}{l}\text { User switches the camera while } \\
\text { chatting }\end{array}$ \\
\hline T6 & Reconnect & $\begin{array}{l}\text { User reconnects if the connection } \\
\text { is loss }\end{array}$ \\
\hline $\mathrm{T} 7$ & End call & User ends call \\
\hline
\end{tabular}

\section{B. Experimentation}

Two experiments were conducted, A and B. Experiment A, a cognitive walkthrough, aimed to reveal whether or not each application serve blind user and how efficient and effective it is. We did so by asking a blind user to perform all seven tasks as instructed by our researcher. We determined the efficiency by measuring the time used to complete each task (M1), and the effectiveness by number of errors (M2) by the blind user. The error occurred when the user made any mistake using the application. In the case that the application did not serve such function, it would be counted as "task failed" and would not be counted toward error. The blind user in our study is a female volunteer who was born-blind with total blindness, age 21 , undergraduate student majoring in Linguistic. She has moderate experience using video call on Line application on smartphone and Skype on PC among other non-video call software. The experiment was done with Samsung Galaxy S3 that has Android 4.3 and Google Talkback 3.5.2 installed. All the calls were made through $4 \mathrm{G}$ connection where the signals were strong. There were no line-drop issues due to $4 \mathrm{G}$ signal. The versions of video call applications are; Line 4.8.1, Skype 5.0.0, Tango 3.12, Viber 5.1.1.42, WeChat 6.0, and Hangout 2.5.8.

Since most current applications may not be designed to answer video call tasks for blind users, naturally, several tasks may not be accomplished. Thus, we designed Experiment B to follow through every tasks, whether or not they can be accomplished by blind user. Obviously, this experiment must be carried out by sighted user. We measured number of actions required to complete a task and call it "issue action" (M3). In other word, M3 stated how many actions or steps were required to complete the desired task. M4, on the other hand, is the minimum number of swipes or gestures required to complete each task. We then computed "wasted action" from M4 and M5 as follow.

$$
M 5=\frac{M 4-M 3}{M 3}
$$

The metrics are shown in Table II.

\section{Evaluation}

The results from Experiment A and B are shown in Table III and Table IV respectively.

The results from Experiment A showed that none of the applications allows the blind user to accomplish all seven tasks. Among the six applications, Tango outperformed others because our volunteer could accomplish 6 out of 7 tasks. However, Hangouts seems to slightly outdo its competitors in terms of efficiency (M1). Because it took the least amount of time to compete the task in 3 out of 5 tasks. The registration Viber was the most efficient for registration, Line performed best when adding friend function. To make a call, Hangout was the fastest. No significant difference was observed when receiving a call. To switch camera, Hangout again won. To reconnect, the best was Hangout. Finally to end call, Tango seemed to be the most efficient.

\begin{tabular}{clc}
\multicolumn{3}{c}{ TABLE II: ALL METRICS AND ITS DESCRIPTION } \\
\hline \hline Code & \multicolumn{1}{c}{ Description } & Experiment \\
\hline M1 & The time used to complete each task & $\mathrm{A}$ \\
M2 & Number of errors by the blind user & $\mathrm{A}$ \\
M3 & Number of issue action & $\mathrm{B}$ \\
M4 & Minimum number of swipes or gestures & $\mathrm{B}$ \\
& required to complete each task & $\mathrm{B}$ \\
M5 & Wasted action
\end{tabular}


TABLE III: RESULT OF EXPERIMENT A

\begin{tabular}{|c|c|c|c|c|c|c|c|c|c|c|c|c|c|c|}
\hline \multirow[b]{2}{*}{ Application } & \multicolumn{2}{|c|}{ Register } & \multicolumn{2}{|c|}{ " Add a new friend } & \multicolumn{2}{|c|}{ Make a new call } & \multicolumn{2}{|c|}{ "RECEIVE A CALL } & \multicolumn{2}{|c|}{ "Switch camera } & \multicolumn{2}{|c|}{ Reconnect } & \multicolumn{2}{|c|}{ End call } \\
\hline & M1 & M2 & M1 & M2 & M1 & M2 & M1 & M2 & M1 & M2 & M1 & M2 & M1 & M2 \\
\hline Line & 6.15 & 0 & 1.37 & 0 & 0.58 & 0 & 0.08 & 0 & - & - & 1.41 & 1 & - & - \\
\hline Skype & - & - & - & - & 2.19 & 1 & 0.05 & 0 & 1.14 & 0 & 2.41 & 1 & 0.13 & 0 \\
\hline Hangouts & - & - & 1.52 & 1 & 0.38 & 0 & - & - & 0.16 & 0 & 1.04 & 1 & 0.21 & 0 \\
\hline Tango & 7.38 & 0 & - & - & 1.53 & 0 & 0.06 & 0 & 0.21 & 0 & 2.01 & 1 & 0.06 & 0 \\
\hline WeChat & 6.42 & 1 & 3.03 & 0 & 1.42 & 0 & 0.05 & 0 & - & - & 2.18 & 1 & - & - \\
\hline Viber & 4.36 & 0 & 3.55 & 1 & 1.04 & 0 & - & - & - & - & 1.34 & 1 & - & - \\
\hline Average & 6.08 & - & 2.37 & - & 1.19 & - & 0.06 & - & 0.50 & - & 2.13 & - & 0.13 & - \\
\hline
\end{tabular}

TABLE IV: RESULT OF EXPERIMENT B

\begin{tabular}{|c|c|c|c|c|c|c|c|c|c|c|c|c|c|c|c|c|c|c|c|c|c|c|c|c|}
\hline \multirow{2}{*}{ Application } & \multicolumn{2}{|c|}{ Register } & \multicolumn{3}{|c|}{ Add a new friend } & \multicolumn{4}{|c|}{$\begin{array}{c}\text { Make a new video } \\
\text { call }\end{array}$} & \multicolumn{3}{|c|}{ Receive a call } & \multicolumn{3}{|c|}{ Switch camera } & \multicolumn{3}{|c|}{ Reconnect } & \multicolumn{2}{|c|}{ End call } & \multicolumn{4}{|c|}{ Total } \\
\hline & $\begin{array}{c}\mathrm{M} \\
3 \\
\end{array}$ & $\begin{array}{c}\mathrm{M} \\
4 \\
\end{array}$ & $\begin{array}{c}\mathrm{M} \\
5\end{array}$ & $\begin{array}{c}\mathrm{M} \\
3 \\
\end{array}$ & $\begin{array}{c}\mathrm{M} \\
4 \\
\end{array}$ & $\begin{array}{c}\mathrm{M} \\
5\end{array}$ & $\begin{array}{c}\mathrm{M} \\
3 \\
\end{array}$ & $\begin{array}{c}\mathrm{M} \\
4 \\
\end{array}$ & $\begin{array}{c}\mathrm{M} \\
5\end{array}$ & $\begin{array}{c}\mathrm{M} \\
3 \\
\end{array}$ & $\begin{array}{c}\mathrm{M} \\
4 \\
\end{array}$ & $\begin{array}{c}\mathrm{M} \\
5\end{array}$ & $\begin{array}{c}\mathrm{M} \\
3 \\
\end{array}$ & $\begin{array}{c}\mathrm{M} \\
4 \\
\end{array}$ & $\begin{array}{c}\mathrm{M} \\
5\end{array}$ & $\begin{array}{c}\mathrm{M} \\
3 \\
\end{array}$ & $\begin{array}{c}\mathrm{M} \\
4 \\
\end{array}$ & $\begin{array}{c}\mathrm{M} \\
5\end{array}$ & $\begin{array}{c}\mathrm{M} \\
3 \\
\end{array}$ & $\begin{array}{c}\mathrm{M} \\
4 \\
\end{array}$ & $\begin{array}{c}\mathrm{M} \\
5\end{array}$ & $\begin{array}{c}\mathrm{M} \\
3\end{array}$ & $\begin{array}{c}\mathrm{M} \\
4 \\
\end{array}$ & $\begin{array}{c}\mathrm{M} \\
5\end{array}$ \\
\hline Line & 6 & $\begin{array}{c}27 \\
5\end{array}$ & 45 & 6 & 21 & 2.5 & 3 & 23 & 6.7 & 1 & 5 & 4 & 1 & 1 & 0 & 4 & 25 & 5.3 & 1 & 4 & 3 & 22 & 354 & 15 \\
\hline Skype & 9 & 22 & 1.4 & 6 & 13 & 1.2 & 4 & 15 & 2.8 & 1 & 2 & 1 & 2 & 3 & 0.5 & 3 & 11 & 2.7 & 1 & 5 & 4 & 26 & 71 & 1.7 \\
\hline Hangouts & 13 & 63 & 3.8 & 3 & 4 & 0.3 & 3 & 10 & 2.3 & 1 & 2 & 1 & 1 & 4 & 3 & 2 & 8 & 3 & 1 & 3 & 2 & 24 & 94 & 2.9 \\
\hline Tango & 6 & 20 & 2.3 & 4 & 24 & 5 & 4 & 17 & 3.3 & 2 & 9 & 3.5 & 1 & 12 & 11 & 1 & 3 & 2 & 1 & 11 & 10 & 19 & 96 & 4.1 \\
\hline WeChat & 6 & 20 & 2.3 & 6 & 20 & 2.3 & 6 & 38 & 5.3 & 1 & 3 & 2 & 1 & 2 & 1 & 2 & 18 & 8 & 1 & 3 & 2 & 23 & 104 & 3.5 \\
\hline Viber & 4 & 16 & 3 & 6 & 29 & 3.8 & 4 & 14 & 2.5 & 1 & 2 & 1 & 1 & 2 & 1 & 2 & 7 & 2.5 & 1 & 6 & 5 & 19 & 76 & 3 \\
\hline Average & 7.3 & 69 & 9.6 & 5.2 & 19 & 2.5 & 4 & 20 & 3.8 & 1.2 & 3.8 & 2.1 & 1.2 & 4 & 2.8 & 2.3 & 12 & 3.9 & 1 & 5.3 & 4.3 & 22 & 133 & 5.1 \\
\hline
\end{tabular}

As for effectiveness (M2), there was almost no difference among all six applications. The blind user made one mistake on each application but for different task. Except for the reconnection task, it was the same mistake that occurred when the user was unable to identify when call was cut off unintentionally. Hence, at this stage, we assumed the same level of effectiveness for all six applications.

The result from Experiment B revealed that for each issue action (M3), the user must swipe, on average, five times to complete an action. Skype surpassed others considering the lowest wasted actions (M5). Line was found to exhibit highest wasted actions due to the registration procedure that require the user to swipe through agreement more than 200 times.

These two experiments showed that switching camera and ending call were the most difficult tasks on smartphone. This was because the interface was designed to show the video on full screen and hide all menus. Hence, it was impossible for the blind user to navigate. Moreover, many tasks require the user to press specific buttons, which is also an impossible task for the blind user. Other obstacles include the fact that some of the menus were not provided for screen reader to read, demanding the users to access through options. Nonetheless, whenever the required actions were placed on the top portion of the menus, blind user found it to be easy to use. Findings from these two experiments are utilized in the next stage.

\section{GUIDELINE FOR USER INTERFACE FOR THE BLINDS}

The findings from the previous step were analyzed in order to propose a guideline to design user interface (UI) for the blinds. We considered WCAG 2.0 as our basis and offer detailed suggestions to help UI designers when designing user interface on smartphones. We considered our work and extension of WCAG for mobile applications. Table V presents the relationship among the findings from previous step, the resulting suggestion or the proposed guideline, and
WCAG with which they are associated.

TABLE V: THE RELATIONSHIP AMONG THE FINDINGS FROM PREVIOUS STEP

\begin{tabular}{lll}
\hline \multicolumn{1}{c}{ Problem } & \multicolumn{1}{c}{ Guideline } & $\begin{array}{c}\text { WCAG } \\
\text { compliance }\end{array}$ \\
\hline $\begin{array}{l}\text { 1. Unable to locate } \\
\text { functions. Eg. Hidden } \\
\text { option menus }\end{array}$ & $\begin{array}{l}\text { Every button and function must } \\
\text { be visible on the screen, can be } \\
\text { read out loud by screen reader, } \\
\text { and accessible by a swiping } \\
\text { motion. }\end{array}$ & WCAG 4.1 \\
& Must &
\end{tabular}

2. Unable to proceed/Unknown status. Eg. System halted when the input was incorrect or loss of call signal

3. Use of

Non-standardized or confusing terms. Eg. Tango uses "Discover" to mean "Contacts". 4. Difficult to locate functions

Must have descriptions or announcement for every error handling and change of status.

WCAG 3.3

Use terms that can be understood WCAG 1.1 by most and add description in captions.

Main and frequent actions should be placed before others. Be mindful that screen reader reads left to right, top to bottom.

5. Excessive number of Must have options. swipes to accomplish a task. Eg. User must swipe more than 200 times to accept an agreement to register.

\section{THE NEW UI}

Following our proposed guideline, we designed a new video call application such that it minimizes swipes, gestures, and complies with WCAG. Our approach was to learn from the six applications we tested. We utilized the functions we found to be beneficial, efficient, and effective. We then combined them with our proposed guideline and verify that they comply with WCAG 2.0. We simulated the newly designed user interface and asked the same volunteer to test 
our application once again. The functions for each of the tasks are shown in Table VI, while the new UI is shown in Fig. 1.

We asked the same volunteer to evaluate our UI following Experiment A's scheme. Table VII provides the results of the experiment compared with the six applications we tested earlier. We found overall improvement of $53.15 \%$, while Registration task yielded highest improvement at $64.22 \%$. Though the tasks of Receive call and End call showed negative improvements, it is noted that the time difference was 0.01-0.02 seconds, which was unnoticeable by users. Most importantly, our proposed solution suggested minimum swipes and ensured accessibility.

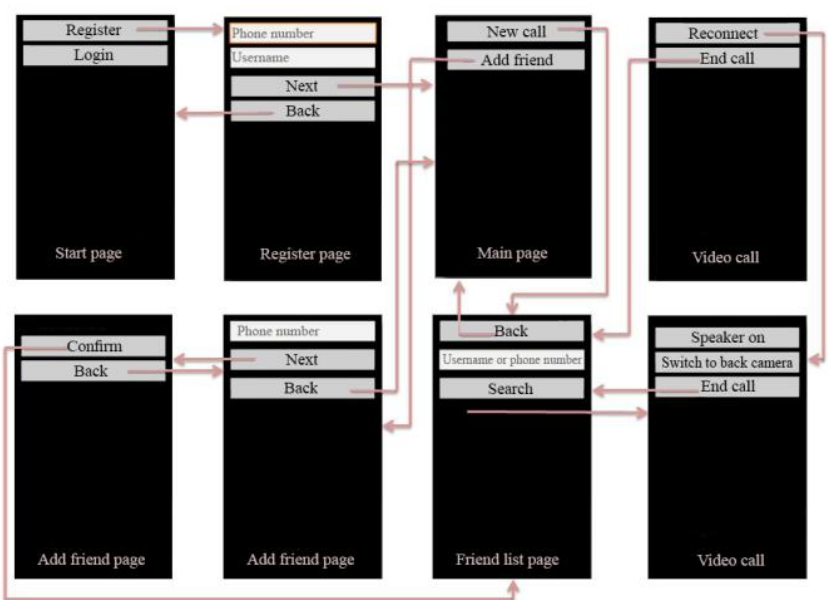

Fig. 1. New UI design.

TABLE VI: THE FUNCTIONS FOR EACH OF THE TASKS

\begin{tabular}{cll}
\hline \hline Task & \multicolumn{1}{c}{ Input field } & \multicolumn{1}{c}{ Based applications } \\
\hline T1 & Username & Tango \\
& Phone number & Line \\
& & WeChat \\
& & Viber \\
T2 & Phone number & All \\
T3 & Username or phone number & All \\
T4 & Accept button & Line \\
& Decline button & WeChat \\
T5 & Switch camera button & Skype \\
& & Hangouts \\
& & Tango \\
T6 & Reconnect button & Tango \\
& End call button & \\
T7 & End call button & Skype \\
& & Hangouts \\
& & Tango \\
\hline \hline
\end{tabular}

TABLE VII: THE RESULTS OF THE EXPERIMENT COMPARED WITH THE SIX APPLICATIONS

\begin{tabular}{cccc}
\hline \hline Task & $\begin{array}{c}\text { Best of } 6 \\
\text { Applications }\end{array}$ & $\begin{array}{c}\text { Our proposed } \\
\text { interface }\end{array}$ & $\begin{array}{c}\% \\
\text { Improvement }\end{array}$ \\
\hline T1 & 4.36 & 1.56 & 64.22 \\
T2 & 1.37 & 1.05 & 23.36 \\
T3 & 0.58 & 0.29 & 50.00 \\
T4 & 0.05 & 0.06 & -20.00 \\
T5 & 0.16 & 0.07 & 56.25 \\
T6 & 1.04 & 0.46 & 55.77 \\
T7 & 0.06 & 0.08 & -33.33 \\
\hline \hline
\end{tabular}

\section{CONCLUSION}

It is very important to consider all kind of users when designing user interface. Our work was focused on video call application on Android smartphone to help people with visual disabilities to communicate with their assistants for navigation help and more. The preliminary part of our study showed that the existing applications failed to serve this group of users, and led to the later parts where we proposed the guideline as a solution and simulated it to compare with those popular applications. We are working on implementing the application on Android and make it available to all.

\section{REFERENCES}

[1] Apple Inc. (2015). Accessibility: VoiceOver for iOS. [Online]. Avaliable: http://www.apple.com/accessibility/ios/voiceover/.

[2] Google Inc. (2015). Android accessibility. [Online]. Avaliable: https://support.google.com/accessibility/android/answer/6007100.

[3] J. Lazar et al., "What frustrates screen reader users on the web: A study of 100 blind users," International Journal of Human-Computer Interaction, vol. 22, no. 3, pp. 247-269, 2007.

[4] E. Blass. (June 2013). Accessibility options flourish for modern mobile devices. USA Today. [Online]. Available: http://www.usatoday.com/story/tech/2013/06/02/smartphone-accessib ility-for-the-blind/2373611/.

[5] S. Chiti and B. Leporini, Accessibility of Android-Based Mobile Devices: A Prototype to Investigate Interaction with Blind Users, in Computers Helping People with Special Needs, K. Miesenberger, Berlin Heidelberg: Springer, pp. 607-614, 2012.

[6] M. G. Paciello, Web Accessibility for People with Disabilities, p. 392, 2000.

[7] The Government of the Hong Kong Special Administrative Region, Mobile Applications Accessibility Handbook, Hongkong, 2011.

[8] T. Hollingsed and D. G. Novick, "Usability inspection methods after 15 years of research and practice," in Proc. the 25th Annual ACM International Conference on Design of Communication, El Paso, Texas, USA, 2007, pp. 249-255.

[9] J. Nielsen, Usability Inspection Methods, New York, NY: John Wiley and Sons, 1994.

[10] J. Rieman, M. Franzke, and D. Redmiles, "Usability evaluation with the cognitive walkthrough," in Proc. Conference Companion on Human Factors in Computing Systems, Denver, Colorado, USA, 1995, pp. 387-388.

[11] G. Pauline, Usability Evaluation: Methods and Techniques: Version 2.0, University of Texas, 2002.

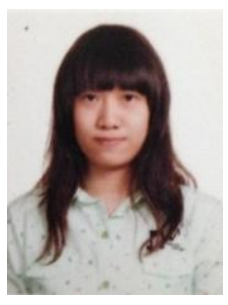

Nutnicha Maneesaeng is a graduate student, majoring in computer engineering, the Department of Computer Engineering, Faculty of Engineering, Chulalongkorn University, Bangkok, Thailand.

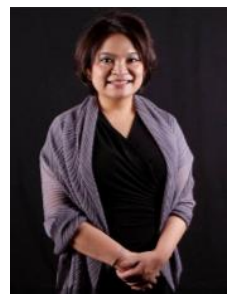

Proadpran P. Punyabukkana is an assistant professor in computer engineering, Chulalongkorn University, Bangkok, Thailand. She is a principle investigator in assistive technology research group.

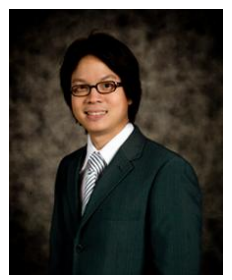

Atiwong Suchato is an assistant dean working at Engineering, Chulalongkorn University. He leads spoken language system research group at the Department of Computer Engineering, Chulalongkorn University. 